\title{
Generation Y: Investigation of Their Role in the Contemporary Life Conditions and Job Market
}

\author{
Adamou Argiro', M.A. \\ Katsarou Danai-Eleni ${ }^{1}$, M.A. \\ Koffas Stefanos ${ }^{1 *}$, Dr. \\ Aspridis George ${ }^{1}$, Assoc. Prof. Dr. \\ Tsiotas Dimitrios ${ }^{2}$, Dr. \\ Sdrolias Labros ${ }^{1}$, Prof. Dr. \\ ${ }^{1}$ Department of Business Administration, \\ Technological Educational Institute of Thessaly, Larissa-Greece \\ ${ }^{2}$ Polytechnic School, University of Thessaly, Volos-Greece \\ ${ }^{*}$ Corresponding Author
}

Doi: $10.2478 / \mathrm{mjss}-2018-0044$

\section{Abstract}

Human evolution in connection with contemporary globalization has created a new Generation: Generation Y. It consists of young people with specific qualitative characteristics and abilities, as well as a broad-minded and extrovert approach to their lives. Nevertheless, they were unlucky enough to be born and grow up in a period of intense economic crises and social upheaval. As a result they face, especially now, the spectrum of the total breakdown of job prospects and established labour rights; consequently they resort to the less frustrating reflection, that of obligatory migration. In order to better understand this Generation it was deemed necessary to develop and send a questionnaire to young people in Greece and abroad. The use and analysis of the research provides the opportunity to form a complete picture of the extent and manner in which the economic and social uncertainty influenced the development of their character, the differences in their mentality, as well as their true opinion of their own generation. The results are assessed to be very useful for understanding them and their role in the prevalent life conditions and especially the job market.

Keywords: Generation Y, Distinguishing Characteristics, Work Environment, Exploratory Approach, Comparative Approach

\section{Introduction}

The understanding of generations is based on the importance and continuity of the historical process and the various events of each time -especially traumatic ones- as well as on the resulting conscience, thus suggesting that the members of a generation are bound together by the experience and remembrances of those events, by the common and self-evident perceptions they share, but also by the demographic transformations and consequent impact (Bourdieu, 1993; Mannheim, 1997; Edmunds and Turner, 2005:560).

As humanity evolves and develops, we undoubtedly experience a series of significant 
changes: changes in the environment, in our conscience, our behaviour, our goals and pursuits. As we grow older, we are being replaced by a younger version of ourselves; a younger generation. It is the Generation $Y$ or Millennials as they are more widely known. They are called Generation $Y$, which follows the letter " $X$ " in the alphabet, as Generation $Y$ was preceded by the renowned Generation X; those born between 1962 and 1975. Their name was the result of the difficulty to define them: children of the '70s and ' 80 s, apolitical, feckless and hedonistic, strangers to the banners and the fighting spirit of the demonstrations that had characterized the previous generations, they were an enigma to analysts; a form of "unknown $X$ ", hence Generation $X$ (http://www.tovima.gr/politics/article/?aid=86534).

Generation $Y$ is the most populous generation to appear. They want to learn, to develop, and to know "how" and "why". They are especially demanding, always ready for any challenge and change, and at the same time extremely adaptable. They possess more qualitative and quantitative characteristics and skills ever to appear in the workplace and is said that they are here to change the relationship employer-employee forever. They seek moral values at work and worklife balance. Their emphasis is on team effort, corporate social responsibility and on communication within and without the organization. They are characterized by their emphasis on learning and training, they seek answers to all important issues, while they achieve immediate and constructive communication and feedback (Prensky, 2001; Aggelatou, 2013).

As far as Greece is concerned, Generation $Y$ expresses and captures those who have been most significantly afflicted by the country's economic and social crisis over the past years. This is the generation that was born between 1977 and 1994. They are young people with many skills and formal qualifications, as well as extensive specialized technological knowledge and skills; however, due to the impact of the extended economic recession and the repercussions for its macroeconomic mitigation in the labour market they are unable to find work. "As a consequence of the massive unemployment, Generation $Y$ is closely linked to the loss of human capital in mainly the following two forms: first, by the devaluation of abilities and skills due to either lengthy inertia or inaction, or by underemployment in jobs that require less specialization (brain waste), and second, by the mass exodus abroad of the most healthy and productive parts of the country's human resources (brain drain)" (Lazaretou, 2016:34).

According to statistics of the Bank of Greece, between 2008 and June 2016, over 427,000 Greeks between the ages of 15-64 left the country permanently, of whom more than 223,000 belong to the Generation Y. All indications so far point to the fact that the phenomenon continues with the same intensity since 2008 and was further exacerbated after the first semester of 2015 . As Lazaretou (2016) points out in the report of the Bank of Greece, the departure of Greeks abroad in search of employment is a process that is still ongoing without any indication to its conclusion (Lazaretou, 2016).

Given the reports above, the objective of the current article is to study the characteristics of Generation $Y$ and to highlight its role in the contemporary work environment. This is achieved not only by the theoretical literature review, but also by the presentation of the results of a research targeted to young people residing both in Greece and abroad. The results are very important as they clarify further the characteristics of this generation, but also because those may be useful to policy makers involved with labour issues. Moreover, they are useful to the corporate and organizational context for shaping a productive work environment, where Generation $Y$ will be able to utilize its capabilities and serve as added value to the final contribution of each corporation or organization.

\section{The Evolution of Modern Generations Over Time}

To this day, many academics and researchers have made extensive efforts to describe and analyze the culture of the various generations in an attempt to determine and explain the structural inequalities among age groups, cohorts, or entire generations, in order to finally be able to bolster their view that a greater and wider focus on the contextual volatility of genetic identities, rather than a unified structure of consecutive generations, may contribute to the co-existence of an experiencebased general equalization of the cultural and economic sociology of the various generations 
(Pilcher, 1994; Warren and Hauser 1997; Mannheim, 2013; Mead, 2017).

Beginning the analysis of the evolution of modern generations with the "Era of Depression" (includes those born between 1912 and 1921), individuals tended to be extremely conservative; at the same time they were characterized by obsessive saving for harsh times. Their debts were kept low and they used safer financial products. The individuals of this generation felt the responsibility of bequeathing a legacy to their children in order to ensure a better life for them. They were permeated by patriotic views, were strictly work-oriented which they placed even higher than personal pleasure. Additionally, they respected authority and were characterized by a sense of moral obligation (Schroer, 2017).

The people in the next generation were those of World War II (born between 1922 and 1927). It was the generation of heroes, conventional and dedicated, respectful of authority, possessing personal pride and enjoying the diffuse gratitude of every citizen towards them. This was the generation that produced a number of important world leaders (Pendergast, 2009). Furthermore, its members shared a common goal: to win the axis of insatiable and dangerous power. It turned out though that there was an acceptable sense of "postponing" everything, a consequence perhaps of the mental and physical fatigue of the lengthy war (Schroer, 2017).

Moving on to the "Post-War Cohort" (those born between 1928 and 1945), there were significant opportunities in work and education; the war had ended and the post-war economic boom influenced many countries of the world. However, the tensions of the Cold War rose and the ever-increasing dynamic of nuclear war and other unprecedented threats led this generation, during its entire time, to levels of extreme discomfort and uncertainty (Schroer, 2017).

It should be noted that its first part is demarcated by the assassinations of JF Kennedy and Martin Luther King, the landing on the moon, the use of contraceptives and mainly by the Vietnam War in which the Boomers I participated (includes those born between 1946 and 1954) (Pendergast, 2009; Schroer, 2017). The first part of this generation stood up, even if unwillingly, to the war, while the second part identified with "... the children of Spring" and so "... missed the entire point". This generation had good financial opportunities and its members were to a great extent optimistic about the dynamics of their country and even more so for their own lives (Wesner \& Miller, 2008; Schroer, 2017).

The generation of Boomers II or Generation Jones (those born between 1955 and 1965) did not really have the advantages of the Boomers I, such as good jobs, personal opportunities, housing, insurance and others. Both Generation X (born between 1966 and 1976) and the generation of the Boomers II suffered under the long shadows bequeathed to them by the generation of the Boomers I. Sometimes they were even referred to as the Lost Generation. This particular generation left without being able to coordinate or even reverse some of the most novel and extremely intense social and political issues; the crisis of the United Kingdom in the mid ' 80 s, for example, with a number of pressing concerns for a better life and employment, the rise of the pension crisis and of the "grey" vote (Vincent et al, 2000; Blackburn, 2002).

Events that take place during the same period include the "expansion of youth" in the crisis of Iran against the monarchy, the end of the Cold War, the multitude of corporate and state scandals across the world which fueled the mistrust of people against the authorities, but also the first occurrence of a pandemic which literally "froze" the world, that of AIDS (Blackburn, 2002; Edmunds and Turner, 2005; Johnson and Lopes, 2008; Wesner and Miller, 2008; Schroer, 2017).

Generation X was characterized by high levels of skepticism and was undoubtedly the best educated and trained generation, with $29 \%$ of them obtaining at least one degree. Education and increasing maturity resulted in families with a higher attention and realism level than those formed by previous generations; perhaps that was why many children lived without their parents, as they were unable to respond to family demands and restrictions (Schawbel, 2016; Schroer, 2017). These were the teachers, academics, economists, trade unionists, policy makers and even leaders who practiced their professions daily with common sense and dignity. It was a time of relative stability which reflected a rather quiet, though progressive, era in society (Howe \& Strauss, 2000; Pendergast, 2009).

Generation $Y$ followed, which includes those born from 1977 to 1994 . It is the most recent generation that completes the circle of its births with three age sub-groups: Generation Why (born 
between 1982 and 1985, the Millennials (born between 1985 and 1999) and the iGeneration (born between 1999 and 2002) (Pendergast, 2009). It was an especially racist generation and ethnically mixed or confused. It was markedly fragmented and it resembled a diverse audience amplified by the rapid flow of conflicting information on cable channels. As a genealogical model, Generation $Y$ was less stable, since the speed of the internet had led it to a state of complete flexibility both in conscience and style (Lenhart et al., 2007; Pempek et al., 2009).

And finally, Generation Z (those born between 1995 and 2012) for which we may not know much, though we do know plenty about the environment they are growing up in. This very different environment will make the schools of the next generation more different than ever. High technology levels will succeed in permeating the academic world and its members, thus allowing the adaptation of education, as well as the extraction of personal information and experiences of students so they can succeed in identifying and utilizing the various opportunities. The children of Generation $Z$ will grow with highly developed information media and in an environment of computers which will not only be safer, but also more developed compared to that of Generation Y (Schawbel, 2016; Schroer, 2017) (Table 1).

Table 1: The age approach of modern human generations

\begin{tabular}{|l|c|c|c|}
\hline Generation Name & Period of Birth & Period of coming of age & Age at 2017 \\
\hline The Depression Era & $1912-1921$ & $1930-1939$ & $96-105$ \\
\hline World War II & $1922-1927$ & $1940-1945$ & $90-95$ \\
\hline Post-War Cohort & $1928-1945$ & $1946-1963$ & $72-89$ \\
\hline Boomers I or The Baby Boomers & $1946-1954$ & $1963-1972$ & $63-71$ \\
\hline Boomers II or Generation Jones & $1955-1965$ & $1973-1983$ & $52-62$ \\
\hline Generation X or Echo Boomers or Millenniums & $1966-1976$ & $1988-1994$ & $41-51$ \\
\hline Generation Y & $1977-1994$ & $1998-2006$ & $23-40$ \\
\hline Generation Z & $1995-2012$ & $2013-2020$ & $05-22$ \\
\hline
\end{tabular}

Source: Schawbel D., (2016) and Schroer W. J., (2017)

\section{Generation $Y$ and its Main Characteristics}

The Time magazine describes them as the "me me me" generation: narcissistic, obsessed with fame and with themselves at the centre of their attention - selfies, outfits of the day and 4G. They are demanding, adaptable, independent, with multiple skills and ready to change course at any given moment. Their coming of age is delayed, they are described as cynics, a generation which still lives with their families since most of the young people are unemployed (Papadopoulos, 2015). Their networking through social media and the individual behaviours they manifest with particular emphasis and intensity are part of their everyday life, following international trends so they can be insiders. This generation has more qualifications than any other that joined the workforce and are the owners of startups which will change our lives. They are stars from childhood, with pioneering business ideas on paper, which they know how to make successful if they decide to put them in action.

This is the youngest generation in the workplace. They are familiar with social networks, trained during a technological boom both at the workplace and their personal life. Its members are called digital natives rather than digital immigrants. It is the first generation that has lived all its life in a digital and virtual environment, while the use of the internet - beyond its use for social networking and image promotion - is considered crucial in regard to issues related to work and employment (Prensky, 2001; Lenhart et al., 2007; Pempek et al., 2009; Aggelatou, 2013).

Their goal is to work faster and better than other workers, while their employers have, from the very beginning, great expectations of them because they want just and direct managers who will work mostly on the development of the human resources and the business. Furthermore, the members of this generation pursue continuous professional training and seek creative challenges, while they consider their experienced colleagues a vast pool they can utilize in order to obtain 
easily and for free specialized knowledge and skills. Finally, they prefer small goals with strict deadlines so they can take ownership of their tasks (Armour, 2005).

However, beyond their classification as baby boomers, Me generation, Millennials, Y-er, they display - especially in the eyes of older generations - inherent difficulties concerning systematic effort, planned action and efficient implementation. The problem is that they have a "blown up" view of themselves because they have been brought up to believe that anything they do is worthwhile and important. As it is characteristically pointed out, they are pampered for too long, while they should have learnt much earlier that they are not perfect. Its representatives are accused of being spoilt, arrogant and narcissistic and having an unjustified sense that everything is rightfully theirs. Teachers complain that today's students demand constant attention, employers are finding it hard to accept the over-inflated egos of their young employees, while therapists say they see a new generation of patients who are depressed because they cannot reach their extremely high expectations (http://www.tovima.gr/science/article/?aid=476130).

The reason behind it burdens to a great extent the generations that brought them up, which, from the very early years, went too far with augmenting the view of self of the Me generation. Frequent lack of limits and boundaries, extensive praise even for minor efforts, overprotection against mistakes and omissions, difficulty in taking responsibilities and overcautious not to cause psychological trauma explain why the individuals of Generation $Y$ are finding it hard to respond to the demands of the workplace and of life in general.

Therefore, this generation is much less likely to respond to the traditional form of management and control which is still popular with a large proportion of the traditional business managers (Atwood et al., 2010). The reason is that the representatives of this generation have certain weaknesses in regard to the demands of the contemporary workplace. They usually have an overvalued view of self and are full of expectations which are extremely high and beyond their abilities; as a result they break more easily under the pressure of the workplace and life and tend towards despondency and depression. It is for this reason that the management of Generation $Y$ requires special attention and constant feedback (Gibson et al., 2009; Aggelatou, 2013).

According to the views of one of the most fervent critics of the youth, Jean Twenge, author of "Generation Me" and psychologist at the State University of San Diego California, "... In order to find evidence that substantiates the over-inflated Ego of Generation Y, we only have to look at the annual study on American freshmen which consists of 9 million students. It is revealed that $52 \%$ of the participants of 2009 believed that their level of social confidence was above the general population average compared to $30 \%$ of students who believed the same in 1966. Additionally, today's students rate their mental self-confidence, public speaking skills and leadership abilities approximately 50\% higher than their 1966 counterparts" (Twenge, 2014; VIMA science, 2017).

The extreme significance of self-esteem for Generation $Y$ was outlined during an experiment that took place in 2010. A team from the State University of Ohio led by Brad J. Bushman, discovered that students valued a boost to their self-confidence -e.g. to receive a higher grade or accept a compliment- higher than rewards that motivated humanity since its beginnings, such as eating one's favourite food, engaging in sexual activity or seeing a film with one's friends. Furthermore, students rated this additional reward higher than earning money, drinking alcohol or travelling for pleasure. In order to further investigate this fact, the scientists asked students to rate how much they would like each of those rewards as well as the amount of satisfaction they would wish to receive from each. In all cases the first part of the question provided more satisfaction than the second; though, the difference between the two was smaller for rewards that offered a boost to self-esteem (VIMA science, 2017).

Finally, and in regard to the structure of the new families, they accept much more easily diversity and different types of family ties, which result in a terrible increase in divorce rates with significant negative impact on childrearing and family cohesion (Alch, 2008). Rushing to judgement is of course very easy; yet it would be more constructive to undertake open and substantiated criticism, but also to reconsider what has long ago been adopted as supposedly the best way to bring up the children of this generation, as well as the family institution in general (ImmordinoYanget.al., 2012). 


\section{Career and Generation $Y$ in Greece}

In Greece, the Marketing and Communication Department of the Economics University of Athens and www.kariera.gr carried out a relevant research in 2016 with the title "Career and Generation Y". The participants in this research were 5208 young people, representatives of Generation Y, 18-35 years of age, university students and alumni from all of Greece. A structured electronic questionnaire and random sampling were used (Career Guide, 2016).

In this research Generation $Y$ showed that in regard to employment they value career prospects offered by a firm/employer higher, ask for satisfactory pay and opportunities for personal and professional development, an ethical work environment and job security. In relation to their career they show that they have an active attitude, self-manage its course and prefer it to be planned. Furthermore, the preservation of moral values is an important priority and they want to develop networks both within and without the business.

Where HRM is concerned, they want to experience everything in regard to recruitment, the communication of learning opportunities and development, the management of the corporate image, the dissemination of corporate results, the good name and reputation of the company, the matching of the candidate to the corporate values and the advancement of the "work security" culture. The retention and development of the members of Generation Y, calls for formal and informal learning opportunities, design of innovative projects, the existence of a career planning and development system where the active participation of young people is instrumental.

Additionally, this generation wants to be encouraged to participate in inter-departmental projects, but also in programmes for balancing one's personal and work life. Finally, in regard to remuneration, they want open communication and access to the pay structure of the company, information on the salary and benefit packages compared to those offered by competitors and communication of salary growth prospects (Kotter, 1996; Aggelatou, 2013; Career Guide, 2016).

\section{Description of Research Methodology}

The goal of the current research was to study the work needs of young people and at the same time their general priorities in life. To this end a multi-dimensional approach was used and specifically a questionnaire, which proved to be useful for corroborating data of the literature research but also for the extraction of accurate conclusions. The multi-dimensional approach is becoming popular among social researchers who opt for the combination of various methodological approaches in order to utilize the entirety of advantages those can offer (Niglas, 2010). Indeed, this methodological approach is considered to be ideal for accessing the perceptions of the respondents, but at the same time it is also a way for provoking situations that would mobilize those into action (Rodos and Rapanis, 2006; Saunders et al, 2009; Babbie, 2011).

The primary tool for the collection of data was interviews based on a structured questionnaire with specific questions investigating the life and work aspirations of young people belonging to Generation Y. The interview tool was selected as it is considered to be the only way of approaching the perceptions of people and, at the same time, it is a way to provoke situations that would bring those perceptions forward (Woods, 1991). The content, order and purpose of the questions is entirely in the hands of the researcher; at the same time the respondent has the opportunity to expand on issues as desired by describing experiences freely and by expressing his views in general (Magos, 2017).

Indeed, a qualitative interview is a discussion between the interlocutors which depends on the manner that "the interviewer and the interviewee view the semantic context and together they build the meaning of the questions and answers" (Mishler, 1996). With the tool of personal interviews participants were given the opportunity to express and describe particularities of their life and the challenges they face in connection to the work arena, as well as their desires in regard to their professional course and career.

The research sample was selected by using theoretical sampling, according to which individuals or groups are chosen based on their characteristics and their relevance to the research questions (Mason, 2003). The research was conducted using personal interviews in order to collect 
answers to the research questions and the questionnaire data were computerized for further utilization. The recording sheet consisted of three main areas. The first area covered young people's need for employment in Greece or abroad. This need was reflected by questions which investigated their social and financial status and their desire to access the job market. The second area concerned the job priorities young people have set. Briefly, questions in regard to those priorities included the type of company Generation $Y$ wants to work for, whether they would work abroad if the remuneration was higher, the important aspects in the workplace and the salary level they would be satisfied with. The third area concerned how members of Generation $Y$ would characterize Generation $Y$. In the context of the questionnaire, they were asked to do this by using a single word, however during the interview participants were asked to elaborate why they described their generation with that specific word. Indeed, their comments were most interesting.

The research was conducted between October 2016 and May 2017. The participants were 192 students of Greek and British higher education institutes. Participants from the British institutes came from Germany, the United Kingdom, Japan, Malaysia and China. There were significant difficulties involved in the research; for its successful conclusion, the physical presence of the researchers was required at the institutes so as to ensure a more accurate research process, but also to avoid semantic misunderstandings which could have possibly led to mistaken assessments. The participants were divided in three age groups as follows: 48 participants between 18-24 years old in the first group, 96 participants between 25-30 years old in the second group and 48 participants between 31-35 years old in the third group.

\section{Research Results}

It was established that $40 \%$ of Generation Y participants/students in Greece and $46.67 \%$ in the UK do not live with their parents. Of those who do, 33.33\% in Greece stated that they are fine with the arrangement compared to only $20 \%$ of students in British universities who give the same answer. In regard to those still living with their parents, $6.67 \%$ of Greek students and $20 \%$ of British university students stated that they would like to be living alone. Furthermore, $20 \%$ of Greek students said that they are obliged to live with their parents while only $13.33 \%$ of students in the UK gave the same answer.

Hence, it is clear that $60 \%$ of young people in Greece live with their parents either because they are obliged to $(20 \%)$ or willingly, but in reality they would like to live alone $(6.67 \%)$, while $33.33 \%$ have no problems with this. In the UK the proportion of young people living with their parents is smaller by about seven percentage points (53\%), of which $33.33 \%$ are obliged to do so. It can therefore be generally said that the young people in British universities who live with their parents do not seem to consider this arrangement as problematic as the Greek students.

In regard to their employment status, 2/3 of students in Greece work either regularly or occasionally. The percentages for students in the UK are similar, with a difference in the $20 \%$ of students who do not work at all. However, $13.33 \%$ of those who do not work wish that they did, while $33 \%$ choose to not work while studying. Occasional work seems to be more frequent for students in the UK by about 7 percentage points compared to Greece.

In conclusion, Greek students seem to be living, in their majority, with their parents, to be mostly working while studying (2/3) either regularly or occasionally, to be contributing to the household expenses and be pleased about. The respective proportion of students in the UK who live with their parents is much lower, working students are less than in Greece and they do not contribute to the household expenses, as only a third of them does so and happily.

Respondents' answers to questions in regard to their work choices were decisive. Greeks answering the question of whether they would work for the base salary of their country said "yes" at a rate of $40 \%$, while only $7 \%$ of students in the UK did the same. Additionally, answers as to whether they would go anywhere for work, positive answers in the UK were over $53 \%$, while in Greece they just reached $33 \%$. The massive majority of Greek students would prefer to work for businesses in the private sector and would prefer to remain in the country irrespective of the salary; conversely, only $6.67 \%$ of students in the UK would remain in their own country if offered a better paid job abroad. Still, Greek respondents consider working abroad a challenge. 
Concerning the jobs themselves, students both in Greece and the UK consider the salary its most important element; for students in Greece, salary is followed by the workplace environment and personal development, while second in importance for students in the UK are the overall benefits.

Asked whether they believe that their future would be better than that of the previous generation, the majority of students in the UK (66.67\%) answered "Yes, and I will try for the best", while "No, things will get worse" was selected by $46.67 \%$ of Greek students.

In answering a question related to nationality and the "right" to employment, $20 \%$ of Greeks seemed to manifest racist behaviours, while in the UK only 1 in 15 respondents mentioned that only nationals of their own country should work there.

Furthermore, it is worth stating that Greek students start their day earlier than their counterparts in the UK and have much lower salary aspirations; if they had savings they would use them for their family or they would invest them. Students in the UK would choose to spend their savings on entertainment and in regard to finding work they place emphasis on "cold visits".

In regard to searching for information, Greek students stated that they have "abolished" library searches and they use exclusively the internet, while in the UK 6 out of 15 students prefer the library. Finally, all students characterize their generation with meanings of negative connotation and quite paradoxically $33.3 \%$ of them are not even aware that their generation is called Generation $\mathrm{Y}$.

\section{Conclusions}

Generation $Y$ is the youngest and the most qualified generation in the workplace today. They are familiar with social networks, quite well trained and in the midst of a technology boom. They are the generation that wants to evolve, to learn and to know "how" and "why". They claim the unflattering title of "the me generation" since they are being brought up pampered, with praises and constant ego boosts, in what may be considered a well-intended effort to reinforce their self-esteem.

The students participating in the research, members of Generation Y, appear to be living in their majority with their parents, to be working either regularly or occasionally during their studies and to be contributing to the household expenses. The proportion of Generation $Y$ students in the UK who live with their parents is lower than in Greece. Further, working students in the UK are less, while they do not contribute to the household expenses as only a small number of them does so happily.

The differentiation between Greek and foreign students lies in the fact that Greeks seem to be reconciled with even the base salary. Students of other nationalities appear to be dealing with the job issue through a completely different approach and mentality. It seems that young students studying in the UK, invest in education and training, have goals and demand more in regard to the job market and job opportunities than their Greek counterparts.

In order to find employment, students, members of Generation Y, in both Greece and the UK focus on sending a resume by e-mail. The differentiation between Greece and the UK is in the fact that students in the UK select more often, compared to Greeks, the option of "cold calls" to the various companies where they get to emphasize the element of personal contact.

In general, the young people of Generation $Y$ have an over-inflated opinion of themselves and are full of extremely high ambitions and desires. A fundamental conclusion of this research is that all of the respondents, the Generation $Y$ itself seems disappointed and characterized their generation with terms of negative connotations. The various descriptions suggest frustration, fear of what is to come and lack of positive energy for the future.

\section{References}

Aggelatou E., (2013), "Generation Y, Generation of overturning", http:// www. kariera. gr, (08/08/2017) [in Greek]

Alch M. L., (2008), Get ready for a new type of worker in the workplace: The net generation, Supervision, Vol.69 (6), $18-21$

Atwood M. A., Mora J. W., Kaplan A. W., (2010), Learning to lead: Evaluating leadership and organizational learning", Leadership \& Organization Development Journal, Vol. 31(7), 576-595 
Armour S., (2005), “Generation Y: They've arrived at work with a new attitude”, USA Today, Vol. 6, 1-4

Babbie E., (2011), Introduction to Social Research, Athens: Kritiki Publishing [in Greek]

Blackburn R., (2002), Banking on Death or Investing in Life. The History and Future of Pensions, London: Verso Publishing

Bolton R. N., Parasuraman A., Hoefnagels A., Migchels N., Kabadayi S., Gruber T., Loureiro Solnet D. Y.K., (2013), "Understanding Generation $Y$ and their use of social media: A review and research agenda", Journal of Service Management, Vol. 24(3), 245-267

Bourdieu P., (1993), Sociology in Question, London: Sage Publishing

Career Guide, (2016), "Research: Career and Generation Y 2016", http:// www.careerguide.gr/career-geny, (08/08/2017) [in Greek]

Edmunds J. and Turner B. S., (2005), "Global generations: Social change in the twentieth century", The British Journal of Sociology, Vol. 56(4), 559-577

Gibson J. W., Greenwood R. A., Murphy Jr, E. F., (2009),“Generational differences in the workplace: Personal values, behaviors, and popular beliefs", Journal of Diversity Management, Vol. 4(3), 1-8

Howe N. and Strauss W., (2000), Millennials rising: The next great generation, New York: Vintage Books

Immordino-Yang M. H., Christodoulou J. A., Singh V., (2012), "Rest is not idleness: Implications of the brain's default mode for human development and education", Perspectives on Psychological Science, Vol. 7(4), 352-364

Kotter J. P., (1996), Leading change, Boston, Massachusetts: Harvard Business Press

Lazaretou S., (2016), Flight of Human Capital: The Contemporary trend of the Greek migration in the years of crisis, Economical Bulletin, Vol.43, June 2016, 33-58

Lenhart A., Madden M., Rankin-Macgill A, Smith A., (2007), Social networking websites and teens: An overview, Pew Internet \& American Life Project, Washington D. C., 1-44

Mannheim K., (1997), "The Problem of Generations", Collected Works of Karl Mannheim, London: Routledge Publishing

Mannheim K., (2013), Essays Sociology Knowledge, Collected Works of Karl Mannheim, Vol. 5, Abingdon, Oxon: Routledge Publishing

Mead M., (2017), Continuities in Cultural Evolution, Abingdon, Oxon: Routledge Publishing

Niglas K., (2010), "The Multidimensional Model of Research Methodology: An integrated set of continua", Tashakkori A. and Teddlie C. (Eds.), Mixed Methods in Social and Behavioral Research, 2nd Edition, Thousand Oaks, CA: Sage Publishing, 215-236 Papadopoulos D., (2015), Generation Y and career. What they want, what they dream, what they wish, http://www.athensvoice.gr/90571 genia-y-kai-kariera $(12 / 07 / 2016)$ [in Greek]

Pendergast D., (2009),“Generational theory and home economics: Future proofing the profession”, Family and Consumer Sciences Research Journal, Vol. 37(4), 504-522

Pilcher J., (1994), "Mannheim's Sociology of Generations: An Undervalued Legacy", The British Journal of Sociology, Vol.45 (3), 481-495

Prensky M., (2001), "Computer Games and Learning: Digital Game-Based Learning", http://marcprensky.com/marcs-essays/, (02-05-2015)

Rodos K. and Rapanis E., (2006), Statistical research: Methods and applications, Athens: Sideris Publishing [in Greek]

Saunders M., Thornhill A., Lewis A., (2009), Research methods for business students, $5^{\text {th }}$ Edition, NY: Pearson

Schawbel D., (2016), "What Employers Will Worry About in 2017", Fortune Insiders, http://fortune.com/2016/12/28/employers-2017-employee-retention-unemployment/, (14/09/2017)

Schroer W. J., (2017), "Generations X, Y, Z and the others", http://social marketing.org/archives/generations-X$y$-z-and-the-others/, (08/08/2017)

Twenge J., (2014), Generation Me, New York: Atria Paperback

VIMA (1997), Generation Y. Who are they, what they think, what they want, and what they reject, who were born after 1975, http://www.tovima.gr/politics/article/?aid=86534 (21/05/2016) [in Greek]

VIMA science, (2012),"The generation of "I" ",http://www.tovima.gr/ science/article/?aid=476130, (23/09/2012) [in Greek]

Vincent J.A., Patterson G., Wale K., (2000), “Understanding the Grey Vote”, GenerationsReview,Vol.11(1), 9-11

Wesner M. S. and Miller T., (2008), "Boomers and Millennials have much in common", Organizational Development, Vol. 26(3), 89-96 